\title{
STRATEGI MENINGKATKAN DAYA SAING PASAR TRADISIONAL (KASUS REVITALISASI PASAR TRADISIONAL DI KOTA BANJARMASIN)
}

\author{
Oleh \\ Farid Zaky Yopiannor \\ Program Studi Administrasi Negara FISIP Universitas Muhammadiyah Palangkaraya
}

\begin{abstract}
ABSTRAK
This study aims to: (1) Analyze consumers' assessment of traditional markets on the policy to revitalize traditional markets in the city of Banjarmasin, (2) Determine the assessment of the management and traders of traditional markets afterthe revitalization policies are conducted by the Government of Banjarmasin, (3) Identify the internal and external factors affecting the traditional markets in an effort to improve the competitiveness of traditional markets in the city of Banjarmasin, (4) To formulate the strategy options for improving the competitiveness of traditional markets in the city of Banjarmasin, (5) To formulate strategic priorities in an effort to improve the competitiveness of traditional markets in Banjarmasin.

The results show that: (1) the performance of traditional markets in the city of Banjarmasin because the revitalization policy is not optimal; this is proven by the consumers' assessment of the marketing mix variables (marketing mix) 7P which is still low on some attributes, such as product quality factors, promotional products market traditional, traditional market traders and service, (2) the traditional-market revitalization in Banjarmasin is not optimum because it is still limited to procedural and has not touchedthe substantive aspects concerning the increased competitiveness of traditional markets, (3) the priority strategy to enhance the competitiveness of traditional markets are (a) optimizing the arrangement of traders with neat and orderly zoning systems (clusters); (b) optimizing the publication and promotional traditional-market activities post revitalization policies; (c) establishing cooperation with universities through $R \mathcal{E} D$ (Research and Development) of traditional markets.It is suggested that revitalization of traditional markets in the city of Banjarmasin must be comprehensive, focusing on the aspects of business management of professionalmarketing and empowerment of traditional market traders
\end{abstract}

\section{Kata Kunci : Strategi, Daya Saing, Revitalisasi Pasar Tradisional}

\section{PENDAHULUAN}

Pasar tradisional adalah pasar yang dikelola oleh Pemerintah Daerah. Peran pasar tradisional dari waktu ke waktu semakin menurun hingga sekarang. Menurut data dari Kementerian Perindustrian dan Perdagangan Indonesia antara tahun 2007-2011 terjadi penurunan kuantitas pasar tradisional yang cukup signifikan. Pada tahun 2007, jumlah pasar tradisional di Indonesia mencapai 13.450. Tapi, pada tahun 2011, jumlahnya menurun menjadi 9.950.

Faktor eksternal seperti pertumbuhan pasar modern dalam banyak kasus di Indonesia, dikhawatirkan mengancam nilainilai sosial yang tumbuh berkembang di pasar tradisional. Ekspansi pasar modern menyiratkan pengejawantahan nilai-nilai kebebasan ekonomi untuk bersaing saling mematikan (free fight liberalism) yang dapat merusak nilai kebersamaan dan kekeluargaan di pasar tradisional (Santosa, 2012). Di sisi lain kemunduran pasar tradisional dewasa ini juga dipengaruhi oleh faktor internal terkait dengan buruknya pengelolaan internal pasar tradisional, sehingga pasar tradisional masih ' $a k r a b$ ' dengan citra sebagai tempat belanja yang kumuh, semrawut, becek, bau dan sumpek.

Kota Banjarmasin merupakan salah satu kota yang pertumbuhan pasar modernnya cukup pesat, hal ini dikhawatirkan akan mengancam eksistensi pasar tradisional. Dinas Pengelolaan Pasar Kota Banjarmasin melakukan kebijakan revitalisasi dalam rangka meningkatkan daya saing pasar tradisional. Revitalisasi ini diasumsikan akan mampu mengembalikan fungsi-fungsi pasar tradisional di Kota Banjarmasin yang terindikasi mengalami kemunduran. 
LANDASAN TEORIS

Konsep Strategi

Perumusan strategi bisa menggunakan beberapa alat, salah satunya adalah Analisis SWOT. Analisis SWOT (SWOT analysis) merupakan metode perencanaan strategis yang digunakan untuk mengevaluasi faktor-faktor Kekuatan (Strentghs), Kelemahan (Weaknesses), Peluang (Opportunities), dan Ancaman (Threats) yang mungkin dihadapi dalam mencapai tujuan kegiatan usaha atau institusi dalam skala yang lebih luas.

\section{Konsep Daya Saing}

Barney (2001) memaparkan mengenai indikator empiris yang memiliki potensi sumber daya perusahaan untuk menghasilkan keuntungan kompetitif yang berkelanjutan adalah nilai, kelangkaan, sulit ditiru oleh perusahaan pesaing dan keberadaan barang pengganti. Faktor-faktor yang harus dimiliki untuk mencapai keunggulan komparatif adalah teknologi, produktivitas yang tinggi, tingkat entrepreneurship yang tinggi, kualitas barang yang diproduksi, promosi meluas yang gencar, tenaga kerja terampil yang profesional, kreativitas dan motivasi yang tinggi. Indikator penilaian daya saing dalam penelitian ini diperoleh berdasarkan 3 faktor yaitu, pengelolaan internal pasar tradisional, kualitas produk pasar tradisional dan pangsa pasar tradisional.

\section{Konsep Pemasaran (Marketing Concept)}

Menurut Kotler (2009:10) "Pemasaran adalah proses sosial yang dengan proses satu individu dan kelompok mendapatkan apa yang dibutuhkan dan inginkan dengan menciptakan, menawarkan, dan secara bebas mempertukarkan produk dan jasa yang bernilai dengan pihak lain". Dunia pemasaran mempunyai banyak strategi untuk mencapai tujuan pemasarannya. Salah satu strategi itu adalah bauran pemasaran (marketing mix). Bauran pemasaran (marketing mix) merupakan salah satu alat yang tepat untuk mengelola seluruh variabel yang berada di bawah kendali pemasar guna mempengaruhi transaksi di pasar. Dari bauran pemasaran (marketing mix) $7 \mathrm{P}$ ini peneliti mengembangkan menjadi beberapa indikator sebagai alat mengukur penilaian kinerja pasar tradisional pasca revitalisasi.

\section{Konsep Pasar Tradisional dan Pasar Modern}

Pasar tradisional menurut Polanyi (2003:77) adalah sebagai tempat bertemu untuk melakukan barter atau membeli dan menjual, dan terjadi proses tawar-menawar. Pasar modern, menurut Kotler (2003) adalah pasar yang dikelola oleh manajemen yang lebih profesional dengan kapasitas besar, margin keuntungan yang kecil, namun memiliki volume penjualan yang besar, dan menggunakan sistem swalayan.

\section{Konsep Revitalisasi Pasar Tradisional}

Revitalisasi pasar tradisional yang komprehensif adalah berlandaskan kepada konsep ekonomi pancasila (kerakyatan). Revitalisasi bukanlah sebatas mengejar efisiensi dan efektivitas seperti 'mempercantik' gedung pasar semata, namun juga harus menyentuh hal-hal mendasar secara komprehensif. Upaya ini harus mampu memperbaharui semangat dan etos kerja pedagang pasar, agar dapat memperbaiki kinerja dalam berjualan, mampu mengelola manajemen keuangan, mampu bersatu mengembangkan manajemen kelembagaan pengelola pasar, menjadi lebih berkinerja dalam meningkatkan pangsa pasar yang dikelolanya (Mubyarto, 1997).

\section{METODE PENELITIAN \\ Pendekatan Penelitian}

Pendekatan yang digunakan dalam penelitian ini adalah merujuk pada prinsipprinsip penelitian deskriptif dengan desain penelitian survey. Survey dianggap relevan untuk meliput sikap dan penilaian konsumen dan pedagang pasar tradisional terhadap kinerja pasar tradisional pasca revitalisasi. 


\section{Instrumen Penelitian}

Kuesioner dalam penelitian ini dibagi 2, yaitu kuesioner yang ditujukan kepada konsumen pasar tradisional dan pedagang pasar tradisional. Kuesioner pertama terdiri dari 21 item pertanyaan yang telah dibuat berdasarkan indikator dari 7P. Kuesioner kedua berisi daftar pertanyaan terkait strategi SWOT.

\section{Teknik Analisis Data}

Untuk tujuan penelitian pertama digunakan teknik analisis statistik deskriptif. Selanjutnya tujuan penelitian kedua yaitu untuk mengetahui strategi meningkatkan daya saing pasar tradisional penulis akan menggunakan matriks SWOT untuk menganalisis faktor-faktor strategis baik internal maupun eksternal yang ada di pasar tradisional.

\section{PEMBAHASAN}

\section{Analisis Bauran Pemasaran (Marketing Mix) Pasar Tradisional}

\section{Produk (Product)}

Bauran pemasaran produk terbagi atas tiga indikator, yaitu: kelengkapan, kualitas dan kesegaran produk. Penilaian konsumen terhadap aspek produk di pasar tradisional Kota Banjarmasin adalah rata-rata kurang. Menurut konsumen pasar tradisional masih kurang dalam hal kelengkapan dan kualitas produk yang didagangkan.

\section{Harga (Price)}

Bauran pemasaran harga terdiri dari tiga indikator, yaitu: harga sesuai dengan kualitas; harga dibawah pasar modern; dan harga produk sesuai dengan harga pasaran. Rata-rata konsumen menilai baik ketiga indikator tersebut. Persentase terbesar penilaian konsumen adalah pada indikator harga pasar tradisional berada di bawah pasar modern.

\section{Promosi (Promotion)}

Bauran pemasaran promosi terdiri dari tiga indikator, yaitu: memberikan potongan harga; publikasi yang cukup; promosi dari mulut ke mulut. Penilaian konsumen rata-rata di tiap pasar adalah kurang. Hal ini menunjukan indikator promosi menjadi sebuah kelemahan tersendiri bagi pasar tradisional.

\section{Tempat (Place)}

Bauran pemasaran tempat terdiri dari tiga indikator, yaitu: lokasi pasar strategis; kemudahan askes; dan kapasitas parkir. Penilaian konsumen di keempat pasar yang menjadi sampel rata-rata sama yaitu baik. Lokasi pasar tradisional di Kota Banjarmasin secara umum adalah strategis.

\section{Orang (People)}

Bauran pemasaran orang diukur dari tiga indikator yaitu, pedagang ramah, tanggap pada keluhan, dan pengetahuan pedagang terhadap produk. Penilaian konsumen pasar tradisional terhadap beberapa indikator people masih dirasa kurang.

6. Proses (Process)

Bauran pemasaran proses, dibagi atas tiga indikator pengukuran yaitu transaksi sederhana, kebebasan memilih produk, dan antrian pembayaran relatif mudah. Penilaian konsumen terhadap indikator ini sudah sangat baik. Sebagian besar konsumen menyatakan banyak kemudahan dalam melakukan transaksi jual-beli di pasar tradisional.

\section{Bukti Fisik (Physical Evidence)}

Bauran pemasaran bukti fisik terdiri dari tiga indikator pengukuran, yaitu ruang pasar bersih, penataan ruang rapi, dan pencahayaan pasar baik. Berdasarkan Penilaian konsumen terhadap bukti fisik di empat pasar tradisional yang dijadikan sampel adalah beragam. Di pasar kuripan dan telawang penilaian konsumen dalam hal bukti fisik masih sangat kurang. Pencahayaan yang kurang baik juga salah satu yang dikeluhkan konsumen di pasar kuripan, terutama di lantai 1 yang menyediakan lauk pauk dan sayurmayur. 


\section{Analisis SWOT Pasar Tradisional}

Hasil analisis SWOT faktor kekuatan (strengths) diuraikan pada tabel berikut.

Tabel 4.9

Analisis SWOT Faktor

\begin{tabular}{|c|c|c|c|c|}
\hline & tradisional. & & & \\
\hline 7. & $\begin{array}{lr}\text { Pedagang } & \text { kurang } \\
\text { ramah\& } & \text { tanggap } \\
\text { terhadap } & \text { keluhan } \\
\text { konsumen\&pengetah } \\
\text { uan pedagang } & \text { kurang } \\
\text { terhadap } & \text { produk } \\
\text { yang } & \text { mereka } \\
\text { dagangkan. } & \end{array}$ & 3,7333 & 0,1171 & 0,4373 \\
\hline \multirow[t]{2}{*}{8.} & $\begin{array}{lr}\text { Belum } & \text { ada } \\
\text { pembagian } & \text { zonasi } \\
\text { produk } & \text { yang } \\
\text { didagangkan. } & \\
\end{array}$ & 4,3666 & 0,1370 & 0,5983 \\
\hline & & & 1,000 & 4,0146 \\
\hline
\end{tabular}

Berdasarkan hasil perhitungan dari nilai tertimbang faktor lingkungan internal dalam peningkatan daya saing pasar tradisional yaitu faktor kekuatan dikurangi dengan faktor kelemahan diperoleh nilai $X$ sebagai sumbu horizontal, 3,6415-4,0146= 0,3731 . Jadi, nilai sumbu $X$ dalam diagram SWOT dalam peningkatan daya saing pasar tradisional di Kota Banjarmasin adalah sebesar -0,3731. Berdasarkan hasil tersebut terlihat jelas faktor kekuatan yang lebih rendah daripada faktor kelemahan. Perhitungan ini mengisyaratkan keadaan internal pasar tradisional yang lemah.

\section{Analisis Faktor Lingkungan Eksternal}

Hasil analisis SWOT faktor peluang digambarkan secara rinci melalui tabel berikut.

Tabel 4.11

Analisis SWOT Faktor Peluang

\begin{tabular}{|c|c|c|c|c|}
\hline No. & $\begin{array}{l}\text { Analisis Peluang } \\
\text { (Opportunities) }\end{array}$ & Rating & Bobot & Tertimbg \\
\hline 1. & $\begin{array}{l}\text { Studi banding } \\
\text { pengelolaan pasar } \\
\text { tradisional. }\end{array}$ & 4,1166 & 0,1730 & 0,7125 \\
\hline 2. & $\begin{array}{lr}\text { Adanya } & \text { pihak } \\
\text { swasta } & \text { untuk } \\
\text { kerjasama } & \\
\text { pembangunan } & \\
\text { pasar. } & \end{array}$ & 4,4166 & 0,1857 & 0,8201 \\
\hline 3. & $\begin{array}{ll}\text { Letak } & \text { Kota } \\
\text { Banjarmasin } & \text { yang } \\
\text { strategis. } & \\
\end{array}$ & 4,0333 & 0,1695 & 0,6839 \\
\hline 4. & $\begin{array}{l}\text { Pertumbuhan } \\
\text { pemukiman } \\
\text { penduduk di Kota } \\
\text { Banjarmasin. }\end{array}$ & 3,7166 & 0,1562 & 0,5808 \\
\hline
\end{tabular}

\begin{tabular}{|c|c|c|c|c|}
\hline No. & $\begin{array}{l}\text { Analisis Kelemahan } \\
\text { (Weaknesses) }\end{array}$ & Rating & Bobot & $\begin{array}{l}\text { Tertim } \\
\text { bg }\end{array}$ \\
\hline 1. & $\begin{array}{ll}\text { Kelembagaan } & \\
\text { pedagang } & \text { pasar } \\
\text { tradisional lemah } & \text { leman modal } \\
\text { dengaha } \\
\text { yang terbatas. }\end{array}$ & 4,4333 & 0,1391 & 0,6167 \\
\hline 2. & $\begin{array}{l}\text { Dinas Pengelolaan } \\
\text { Pasar terikat dengan } \\
\text { aturan birokratis. }\end{array}$ & 3,5333 & 0,1108 & 0,3917 \\
\hline 3. & $\begin{array}{ll}\text { Keberadaan } & \text { oknum } \\
\text { pedagang } & \text { kurang } \\
\text { kooperatif. } & \\
\end{array}$ & 3,9833 & 0,125 & 0,4979 \\
\hline 4. & $\begin{array}{lr}\text { Event } & \text { terbatas, } \\
\text { promosi } & \text { minim, } \\
\text { edukasi } & \text { konsumen } \\
\text { kurang, dan jaringan } \\
\text { lemah. }\end{array}$ & 3,8333 & 0,1202 & 0,4611 \\
\hline 5. & $\begin{array}{lr}\text { Citra } & \text { pasar } \\
\text { tradisional } & \text { kotor, } \\
\text { kumuh, } & \text { bau\& } \\
\text { semrawut. } & \\
\end{array}$ & 4,4166 & 0,1386 & 0,6121 \\
\hline 6. & $\begin{array}{l}\text { Kelengkapan dan } \\
\text { kualitas produk pasar }\end{array}$ & 3,5666 & 0,1119 & 0,3992 \\
\hline
\end{tabular}




\begin{tabular}{|l|l|l|l|l|}
\hline 5. & Otonomi Daerah & 3,9666 & 0,1667 & 0,6615 \\
\hline 6. & $\begin{array}{l}\text { Perkembangan } \\
\text { IPTEK }\end{array}$ & 3,5333 & 0,1485 & 0,5249 \\
\hline & & & 1,000 & 3,9840 \\
\hline
\end{tabular}

Sumber: Analisis Data Primer

Sedangkan, hasil analisis SWOT faktor peluang digambarkan melalui tabel berikut.

Tabel 4.12

Analisis SWOT Faktor Ancaman

\begin{tabular}{|c|c|c|c|c|}
\hline No. & $\begin{array}{l}\text { Analisis Ancaman } \\
\text { (Threats) }\end{array}$ & Rating & Bobot & $\begin{array}{l}\text { Tertimb } \\
\text { g }\end{array}$ \\
\hline 1. & $\begin{array}{l}\text { Pertumbuhan pasar } \\
\text { modern. }\end{array}$ & 4,4666 & 0,2412 & 1,0774 \\
\hline 2. & $\begin{array}{l}\text { Perubahan gaya } \\
\text { hidup masyarakat. }\end{array}$ & 3,4833 & 0,1881 & 0,6552 \\
\hline 3. & $\begin{array}{l}\text { Keberadaan PKL } \\
\text { ikut memanfaatkan } \\
\text { aset pasar } \\
\text { tradisional. }\end{array}$ & 4,1666 & 0,2250 & 0,9375 \\
\hline 4. & $\begin{array}{l}\text { Perubahan tata } \\
\text { ruang wilayah Kota } \\
\text { Banjarmasin. }\end{array}$ & 3,1833 & 0,1719 & 0,5472 \\
\hline \multirow[t]{2}{*}{5.} & $\begin{array}{l}\text { Aturan jarak pasar } \\
\text { tradisional } \\
\text { \&modern dalam } \\
\text { prakteknya banyak } \\
\text { dilanggar. }\end{array}$ & 3,2166 & 0,1737 & 0,5587 \\
\hline & & & 1,000 & 3,7764 \\
\hline
\end{tabular}

Sumber: Analisis Data Primer

Berdasarkan hasil perhitungan nilai tertimbang, faktor eksternal yang dimiliki dalam upaya peningkatan daya saing pasar tradisional di Kota Banjarmasin adalah hasil dari pengurangan faktor peluang dengan faktor ancaman, yaitu 3.9840-3,7764=0,2076. Dari hasil pengurangan ini menciptakan sumbu Y sebesar 0,2076. Jadi, faktor peluang yang dimiliki dalam upaya peningkatan daya saing pasar tradisional memiliki nilai yang lebih besar daripada faktor ancaman yang dihadapi, yaitu sebesar 0,2076.

Berdasarkan dari hasil penghitungan tersebut diatas yang menghasilkan nilai sumbu $X$ sebesar -0,3731 dan nilai sumbu $Y$ sebesar 0,2076. Sehingga dapat digambarkan dalam diagram SWOT seperti berikut.

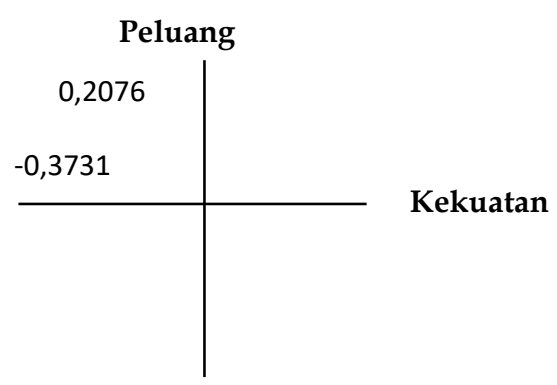

Ancaman

Gambar 4.1 Diagram Hasil Analisis SWOT Pasar Tradisional Kota Banjarmasin

\section{Strategi Meningkatkan Daya Saing Pasar Tradisional}

Berdasarkan asumsi-asumsi yang sudah diuraikan diatas, maka dihasilkan pilihan-pilihan strategis (strategic choices) yang dapat dijelaskan sebagai berikut:

a. Optimalisasi publikasi kegiatan pasar dan promosi pasca revitalisasi.Pemerintah Kota Banjarmasin harus lebih menggalakkan publikasi kegiatan di pasar tradisional.

b. Membangun kerjasama dengan perguruan tinggi melalui litbang (penelitian dan pembangunan) pasar tradisional. Strategi ini bisa dilakukan oleh Pemerintah Kota Banjarmasin dengan menjadikan pengelolaan pasar tradisional di Yogyakarta yang bekerjasama dengan Universitas Gajah Mada (UGM) sebagai role model.

c. Optimalisasi peningkatan pengawasan terhadap produk, standarisasi ukuran dan timbangan. Pemerintah Kota Banjarmasin harus meningkatkan pengelolaan internal pasar yang terkait dengan pengawasan ketat terhadap produk yang dijual dan mengenai standarisasi ukuran dan timbangan.

d. Optimalisasi penataan dengan sistem zoning (klaster) yang rapi dan teratur. Dengan sistem ini para pedagang akan dibagi kepada zona-zona khusus sesuai jenis barang dagangannya, sehingga memudahkan konsumen untuk mencari barang-barang. 
e. Reformasi pengelola pasar perlu dilakukan.Dunia bisnis yang berputar cepat mensyaratkan pengelolaan pasar tradisional dewasa harus penuh dengan inovasi, kreativitas, dan produktivitas dari Pemerintah Kota sebagai suatu kewajiban.

\section{Kesimpulan}

1. Kinerja pasar tradisional di Kota Banjarmasin pasca kebijakan revitalisasi belum optimal. Hal ini dibuktikan dengan penilaian konsumen terhadap variabel-variabel bauran pemasaran (marketing mix) 7P yang masih rendah tas beberapa atribut, seperti faktor kualitas produk, promosi produk pasar tradisional, dan pelayanan pedagang pasar tradisional.

2. Berdasarkan penilaian pengelola pasar dan responden pedagang terhadap indikator-indikator daya saing pasar tradisional pasca revitalisasi belum ada peningkatan daya saing yang optimal. Revitalisasi pasar di Kota Banjarmasin disimpulkan masih sebatas prosedural, belum menyentuh hal-hal yang bersifat substantif seperti peningkatan pengelolaan internal pasar, peningkatan kualitas produk dan perluasan pangsa pasar.

3. Prioritas strategi dalam meningkatkan daya saing pasar tradisional di Kota Banjarmasin adalah sebagai berikut:

a. Optimalisasi penataan pedagang dengan sistem klaster(zoning) yang rapi dan teratur dalam rangka memudahkan konsumen dalam mencari barang-barang yang dibutuhkannya;

b. Optimalisasi publikasi dan promosi kegiatan-kegiatan pasar tradisional pasca revitalisasi melalui media cetak dan elektronik yang bertujuan untuk meningkatkan daya tarik pasar tradisional;

c. Membangun kerjasama dengan perguruan tinggi melalui litbang (penelitian dan pembangunan) pasar tradisional

\section{Referensi}

A.C. Nielsen (2005) Asia Pacific Retail and Shopper Trends 2005 [online] http://www.acnielsen.de/pubs/docu ments/RetailandShopperTrendsAsia2 005.pdf [20 Januari 2015]

Barney, J.B. 2001. Is the resource based "view" a useful perspective for strategic management research? Yes. Academy of ManagementReview, 26(1):41-56.

Baswir, Revrisond, 2010. Ekonomi Kerakyatan Vs Neoliberalisme. Cetakan I. Januari 2010. Yogyakarta; Delokomotif

Indef, 2007. Kajian Dampak Ekonomi Keberadaan Hypermarket terhadap Ritel/ Pasar Tradisional: Ringkasan Eksekutif. Kerjasama dengan Puslitbang Perdagangan DalamNegeri Departemen Perdagangan RI.

Kotler, Donald Haider \& Irving Rein, 1993. Marketing Places. Maxwell Macmillan International, Toronto.

Kotler, P. dan Armstrong, G.M., 2010. Principles of Marketing. 13th (Global) Edition. Pearson Education, Inc., Boston. 2009. Marketing an Introduction, Ninth Edition. New Jersey: Prentice Hall.

Kuncoro,Mudrajad,2008. Pengembangan Pasar Modern dan Tradisional. Gramedia Pustaka Utama.

Malano, Herman, 2011. Selamatkan Pasar Tradisional. PT. Gramedia Pustaka.

Mubyarto, 1997. Ekonomi Rakyat, Program IDT dan Demokrasi Ekonomi Indonesia,Penerbit Aditya Media.

Rahardjo, Dawam, 2004. Ekonomi Pancasila Dalam Tinjauan Filsafat Ilmu (handout). 6 Januari 2004.

Sarman, Mukhtar, 2004. Metodologi Penelitian Sosial. Banjarbaru: Pustaka FISIP Universitas Lambung Mangkurat.

Stanton, William J., 2006. Prinsip Pemasaran, Jilid I (Edisi Ketujuh), Erlangga, Jakarta.

Santosa,Awan.2012.Membatasi Ritel Modern? www.sekolahpasar.org/membatasi-ritel$\underline{\text { modern }}$ [20 Januari 2015 